\title{
Evaluating the Electrical Conductivity and Resistivity of Carbon Nanostructures Embedded in the PLA Matrix
}

\author{
Diogo José Horst ${ }^{1, *}$, (D), Pedro Paulo de Andrade Junior ${ }^{2}$ (D) \\ 1,2 Federal University of Santa Catarina (UFSC), Department of Mechanical Engineering and Sciences, Dona Francisca 8300, \\ Zip Code: 89216-600, Joinville - SC, Brazil \\ * Correspondence diogohorst@gmail.com;
}

Scopus Author ID 55823621400

Received: 9.04.2020; Revised: 7.06.2020; Accepted: 10.06.2020; Published: 15.06.2020

\begin{abstract}
In this work, we evaluated the fabrication and three-dimensional printing (3DP) of conductive filaments intended for designing electronic circuits using fused filament fabrication (FFF). For this $15 \mathrm{wt}$. \% of graphene (GR), carbon black (CB) and carbon nanotubes (CNTs) were embedded into thermoplastic polylactic acid (PLA) resin matrix. Measurements of electrical resistance and conductivity, SEM, DSC, and XRD analysis were used to characterize the materials. The resistivity of the polymer nanocomposites was found to be between 0,7 and $1,4 \Omega / \mathrm{cm}$ and conductivity ranging between 0,71 and $1,42 \mathrm{~S} / \mathrm{cm}$, respectively.
\end{abstract}

Keywords: Carbon nanostructures; conductive filaments; 3D-printing materials; polymer nanocomposites.

(C) 2020 by the authors. This article is an open-access article distributed under the terms and conditions of the Creative Commons Attribution (CC BY) license (https://creativecommons.org/licenses/by/4.0/).

\section{Introduction}

Since globalization has taken place, carbon (in different forms) has been considered a fundamental material in most of the three-dimensional (3D)/four-dimensional (4D) printing applications [1,2,3]. Various methods for the use of graphene by blending it in waste polymers/plastic have been discussed, graphene has been used because of its stimulating properties, which can be regenerated by external forces [4,5] .

3DP has revolutionized the way of manufacturing by designing complex structures in a customized feature that cannot be realized by traditional processing methods. Incoming materials are trying to adopt 3DP techniques that directly fabricate sophisticated entities with multifunctionality like mechanical, electrical, thermal and magnetic properties, etc. [6]. For the realization of advanced materials, 3DP techniques are emerging from single material to composite materials manufacturing by simply introducing the nano- and micro-reinforcements with the matrix $[7,8]$.

The shelf-life performance of PLA filaments for 3DP is limited by aging mechanisms in terms of durability. It was found that the graphene-carbon nanotube fillers enhance the crystallinity, thermal stability, electrical conductivity, and tensile Young's modulus, along with reduced tensile strength, elongation and toughness, compared to the neat PLA. The annealing was found efficient to substantially improve mechanical, thermal, and electrical properties of the aged PLA-based composite filaments; however, the annealing temperature has to be tuned according to the type of carbon nanofiller and the target properties $[9,10]$. 
Inside this context, in this study, we evaluated the fabrication of conductive filaments and the 3DP of circuits, paving the way for fabricating other electronic components such as resistors and sensors.

\section{Materials and Methods}

\subsection{Materials.}

The conductive filaments were prepared in a single screw extruder (Filastruder, GA, USA) by hot mix blending PLA (Braskem, Brazil) with 15 wt.\% of graphene (catalog XFQ021), carbon black (catalog XFI15) and carbon nanotubes (catalog XFS08) (Xfnano, China). The extrusion was performed at temperatures between $140-200{ }^{\circ} \mathrm{C}$, thereby obtaining conductive filaments measuring $1.75 \mathrm{~mm}$ diameter rolled into $1 \mathrm{~kg}$ coils.

\subsection{Electrical measurements.}

The conductive circuit was first designed in CAD (Autocad 2004), and files exported to STL, and digitally loaded into Makerware. The circuits were printed using a desktop machine (Prusa Mendel-I3, USA) with printing temperature at $180-240{ }^{\circ} \mathrm{C}$ and table heating at $60{ }^{\circ} \mathrm{C}$; the feeding speed was $10 \mathrm{~mm} / \mathrm{min}$, and the output measure of the hot end was 0.4 $\mathrm{mm}$. For electrical measurements of resistivity and conductivity, silver paint (Electron Microscopy Sciences, catalog number: 12630) was applied in small areas (width: 1-2 mm; length: 3-4 mm). Some areas of the conductive thermoplastic were subsequently connected to a Keithley source (Model6430). The electrical resistance of the samples was measured using four and two-point methods under an applied voltage of $1 \mathrm{~V}$. The electrical conductivity was measured using a portable conductivity meter (Akso) $[11,12]$.

\subsection{Scanning Electron Microscopy (SEM).}

In SEM analysis, conductive filaments measuring $1 \times 1 \mathrm{~cm}$ were used as test specimens being inserted in specific stubs and covered with a thin gold layer by sputtering using a 10-8 vacuum chamber and then placed in the sample holder of an equipment JEOL JSM-6701F for analysis.

\subsection{X-Ray Diffraction (XRD).}

In XRD analysis, carbon nanostructures in powder form were used, this characterization was performed is a PANalytical Empyrean analytical equipment using copper target $(\mathrm{CuK} \alpha$ $1.5418 \AA$ radiation), $2 \theta$ from $5^{\circ}$ to $70^{\circ}$, with sweep speed of $0.05^{\circ} / \mathrm{s}$, the voltage of $40 \mathrm{kV}$ and $40 \mathrm{~mA}$ current.

\subsection{Differential Scanning Calorimetry (DSC).}

In DSC analysis, samples were weighed $(3.0 \pm 0.5 \mathrm{mg})$ and hermetically sealed in aluminum crucibles being placed in a Shimadzu calorimeter model DSC-60 under an atmosphere of nitrogen, flow $50 \mathrm{ml} \mathrm{min-1;} \mathrm{the} \mathrm{heating} \mathrm{ratio} \mathrm{was} \mathrm{maintained} \mathrm{from}$ $20^{\circ} \mathrm{C} \mathrm{min}-1$ to $550{ }^{\circ} \mathrm{C}$. The heating rate was maintained at $10 \% \mathrm{~min}$ with a nitrogen flow of $100 \mathrm{~mL} / \mathrm{min}$. The equipment was calibrated for temperature with an indium standard $(156.6 \pm$ $0.3{ }^{\circ} \mathrm{C}$ ) through their melting peak. The enthalpy and heat flow were calibrated using the heat of fusion of indium $(28.59 \mathrm{~J} / \mathrm{g} \pm 0.30)$ using the same conditions as the samples. 


\section{Results and Discussion}

\subsection{Fabrication of filaments and circuit.}

Figure 1 shows the machinery used in the production process to obtain the conductive filaments and post-printing circuit:

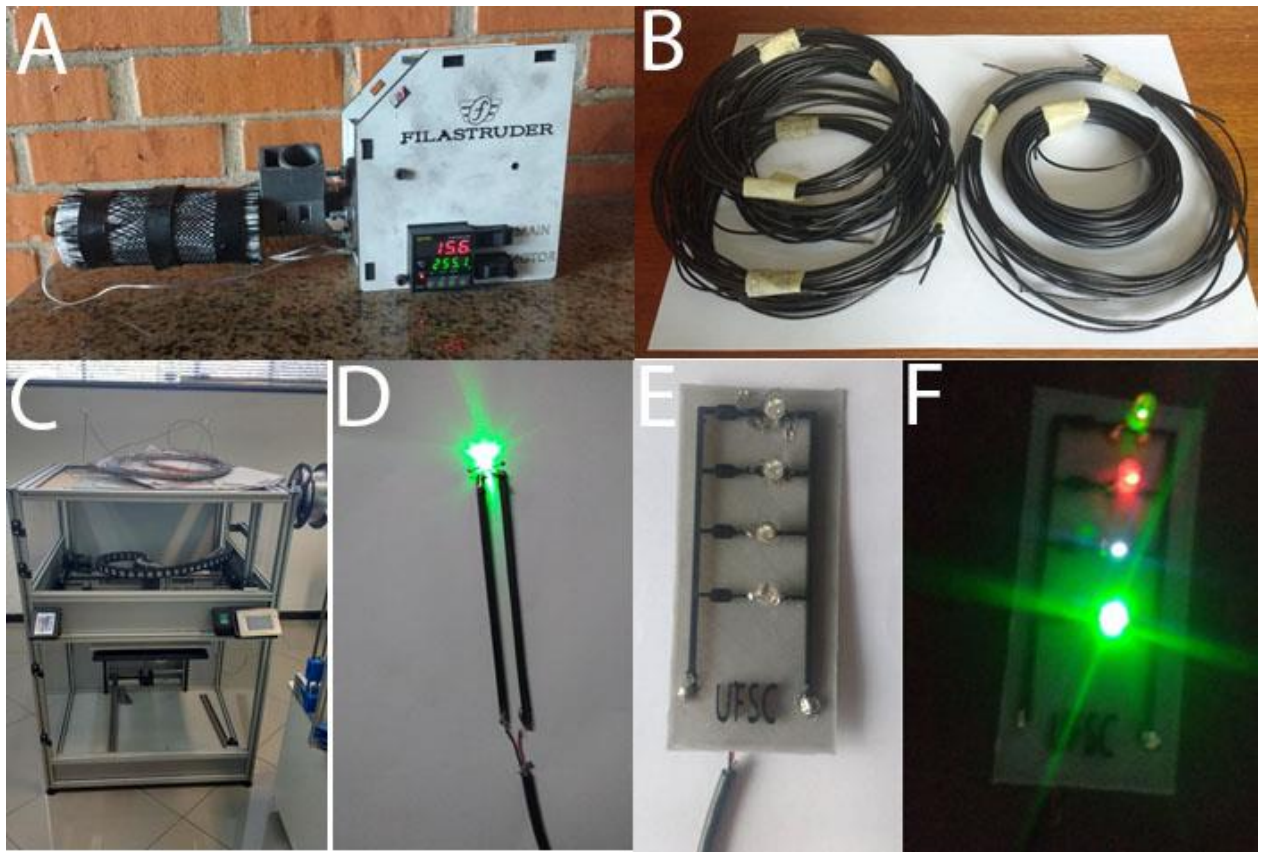

Figure 1. Legend: a) extruder machine; b) conductive filaments obtained; c) 3D printer machine; d) simple circuit lighting one led lamp; e) 3D printed circuit without charging; and f) $5 \mathrm{~V} \mathrm{C} / \mathrm{C}$ charged circuit lightning four led lamps.

\subsection{Electrical measurements.}

Figure 2 shows the electrical resistivity and conductivity of filaments obtained:

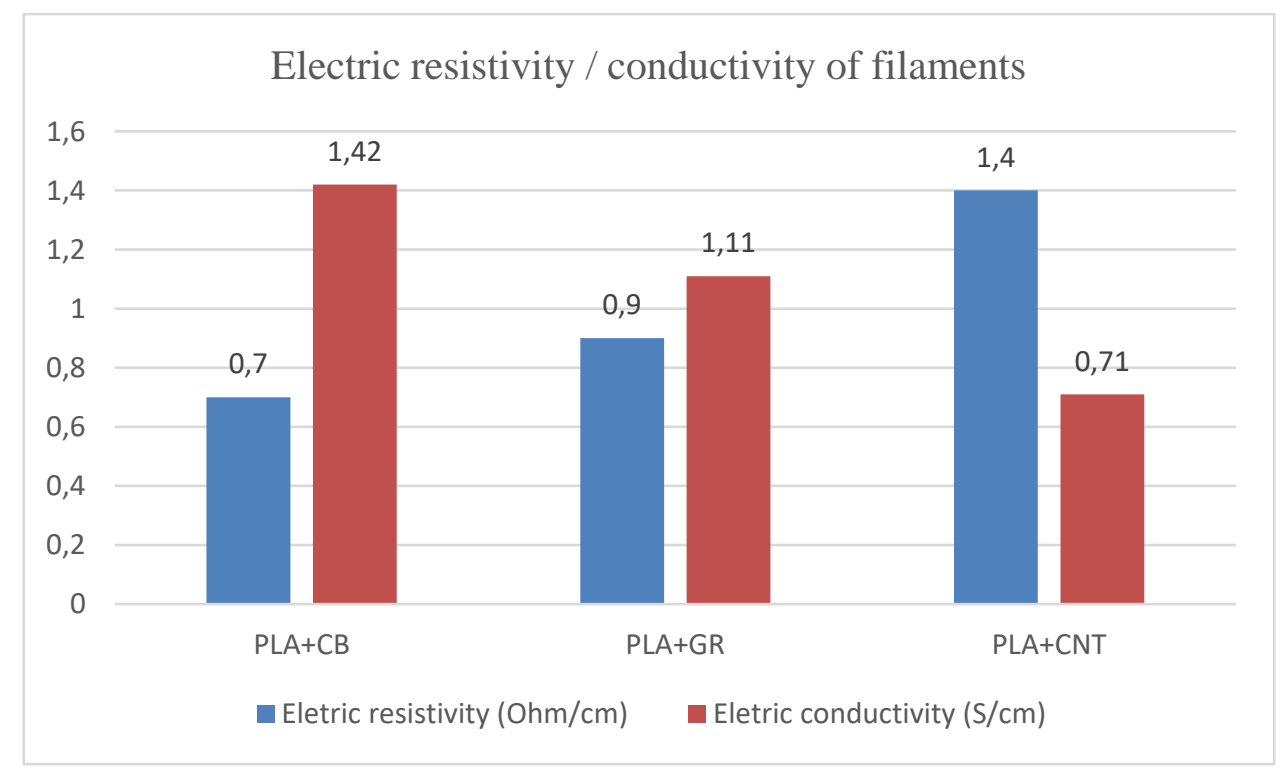

Figure 2. Electrical measurements.

As can be seen in Figure 2, the resistivity was found to be between 0,7 and $1,4 \Omega / \mathrm{cm}$ and the conductivity ranging between 0,71 and $1,42 \mathrm{~S} / \mathrm{cm}$. 


\subsection{Scanning Electron Microscopy (SEM).}

Figure 3 shows the SEM analysis of filaments obtained:

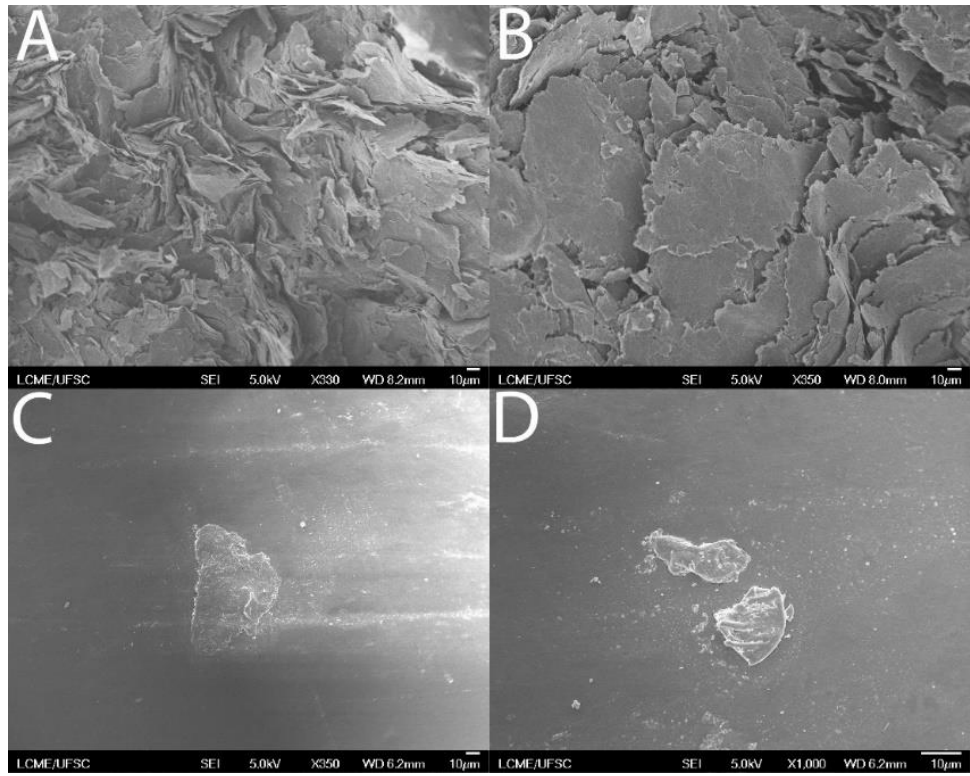

Figure 3. SEM of filaments, the legend: a) cross-session fracture of PLA + GR; b) cross-session fracture of PLA + CNT, c) surface morphology of PLA + CB, and d) surface morphology of PLA + GR.

As can be seen in Figure 3, the particles of GR, CNT, and CB are well dispersed in the polymer matrix. The concentration of 15 wt. $\%$ was already sufficient; in some cases, the formation of particle accumulation was noted in the surface (Figure $3 \mathrm{c}$., and Figure $3 \mathrm{~d}$.)

\subsection{X-Ray Diffraction $(X R D)$.}

Figure 4 shows the X-ray diffraction pattern of carbon nanostructures:

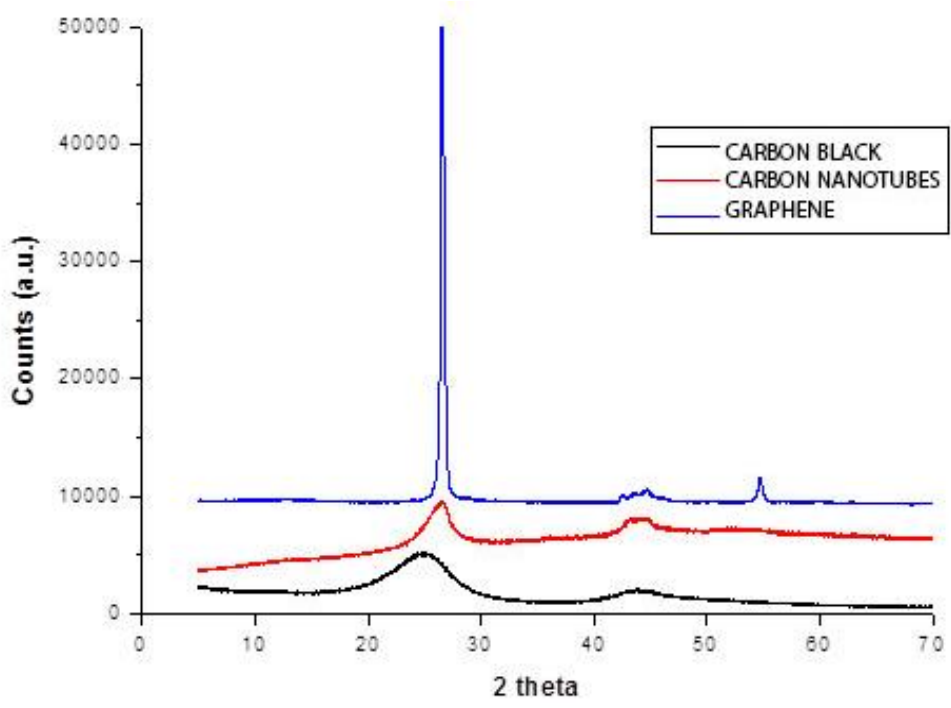

Figure 4. X-ray diffractogram of carbon nanostructures in powder form.

In Figure 4, typical peaks of graphene were observed at $2 \theta$ of $\sim 26 \mathrm{o}$ and $\sim 43 \mathrm{o}$, respectively, which could be indexed to the characteristic peak reflections of graphite from the graphene (JCPDS No. 01-0646) [4]. The peak at 26.061o is attributed to the characteristic peak 
of CNTs in powder form (JCPDS, Card No. 75- 1621) [5]. The peak observed around 26o is due to the appearance of cubic carbon (carbon black) (JCPDS card, No. 00-060-0053) [13].

\subsection{Differential Scanning Calorimetry (DSC).}

Figure 5 shows the DSC of samples:

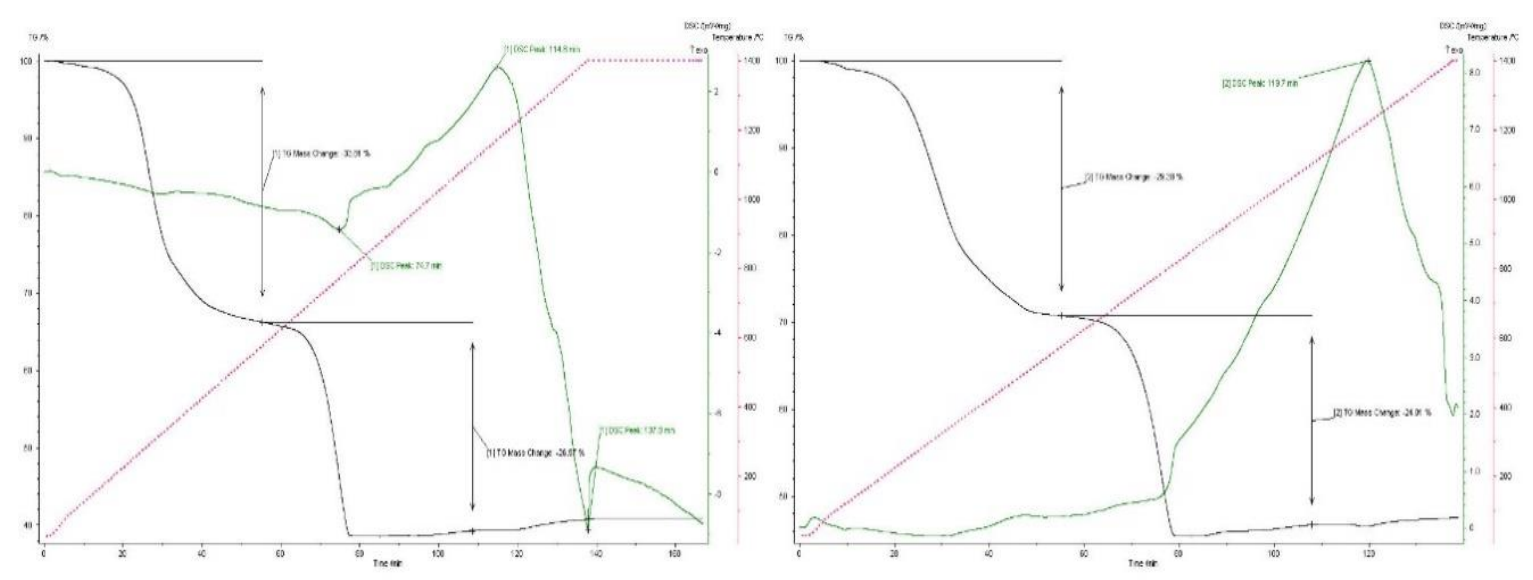

Figure 5. DSC thermograms of samples, at left PLA resin without addition of carbon nanostructures, at right PLA charged with 15 wt. \% of carbon nanostructures.

In Figure 5, the mass change around $55{ }^{\circ} \mathrm{C}$ indicates the glass $(\mathrm{Tg})$ transition of PLA occurs, another mass change around $78,7^{\circ} \mathrm{C}$ indicates that crystallization occurs, in this phase, the molecules still have enough energy to form new bonds. At $108,5{ }^{\circ} \mathrm{C}$ the melting point of this resin begins. In comparison, the addition of carbon nanostructures at $15 \mathrm{wt}$ \% does not affect the thermal behavior of the polymer matrix.

\section{Conclusions}

Due to its inherent electric characteristics, the insertion of these carbon nanostructures into PLA polymer matrix possibilities of the fabrication of conductive filaments allowing the 3DP of electronic circuits. The SEM analysis of morphology revealed that the charges are well incorporated into the PLA thermoplastic resin, and the DSC analysis revealed that its addition does not change the thermal behavior of the same. These very promising results pave the way for the manufacture of new electronic components using these materials. Future works will be developed to investigate the addition of such nanostructures in other polymers in order to verify its electrical measurements. The resistivity of the polymer nanocomposites was found to be between 0,7 and $1,4 \Omega / \mathrm{cm}$ and conductivity ranging between 0,71 and $1,42 \mathrm{~S} / \mathrm{cm}$, respectively.

\section{Funding}

This study was sponsored by CAPES financial code [001].

\section{Acknowledgments}

The authors are grateful for the technical support from the staff of the Federal University of São Paulo (UNIFESP) in DSC work, the LCME-UFSC for technical support during SEM work, and also Technological Institute of Aeronautics (ITA) for their supporting during XRD analysis. 


\section{Conflicts of Interest}

\section{The authors declare no conflict of interest.}

\section{References}

1. Singh, N.; Singh, R.; Sandhu, G.S. Application of Graphene Polymer Blended Feed Stock Filament for 3D/4D Printing. Reference Module in Materials Science and Materials Engineering 2018, https://doi.org/10.1016/B978-0-12-803581-8.10336-4.

2. Horst, D.J.; Andrade Junior, P.P. 3D-Printed Conductive Filaments Based on Carbon Nanostructures Embedded in a Polymer Matrix: A Review. International Journal of Applied Nanotechnology Research 2019, 4(1), article 3, 26-40, https://doi.org/10.4018/IJANR.2019010103.

3. Shao, L-H.; Zhao, B.; Zhang, Q.; Xing, Y.; Zhang, K. 4D printing composite with electrically controlled local deformation. Extreme Mechanics Letters, 2020, 39, 100793, https://doi.org/10.1016/j.eml.2020.100793.

4. Wajahat, M.; Kim, J.H.; Ahn, J.; Lee, S.; Bae, J.; Pyo, J.; Seol, S.K. 3D printing of Fe3O4 functionalized graphene-polymer (FGP) composite microarchitectures. Carbon, 2020, In Press, https://doi.org/10.1016/j.carbon.2020.05.045.

5. Lai, K.C.; Lee, L.Y.; Hiew, B.Y.Z.; et al. Facile synthesis of xanthan biopolymer integrated 3D hierarchical graphene oxide/titanium dioxide composite for adsorptive lead removal in wastewater. Bioresource Technology, 2020, 309, 123296, https://doi.org/10.1016/j.biortech.2020.123296.

6. Zhang, J.; Zhu, S.; Song, K.; Wang, Z.; et al. 3D reduced graphene oxide hybrid nano-copper scaffolds with a high antibacterial performance. Materials Letters, 2020, 257, 127527 , https://doi.org/10.1016/j.matlet.2020.127527.

7. Wang, Y.; Zhang, Y.; Liu, J.; Wang, G.; Pu, F.; et al. Boosting areal energy density of 3D printed all-solidstate flexible microsupercapacitors via tailoring graphene composition. Energy Storage Materials, 2020, In Press, https://doi.org/10.1016/j.ensm.2020.05.034.

8. Guo, H.; Lv, R.; Bai, S. Recent advances on 3D printing graphene-based composites. Nano Materials Science 2019, 1, 101-115, https://doi.org/10.1016/j.nanoms.2019.03.003.

9. Kotsilkova, R.; Petrova-Doycheva, I.; Menzeidov, D.; Ivanov, E.; Paddubskaya, A.; Kuzhir, P. Exploring thermal annealing and graphene-carbon nanotube additives to enhance crystallinity, thermal, electrical and tensile properties of aged poly(lactic) acid-based filament for 3D printing. Composites Science and Technology 2019, 181, https://doi.org/10.1016/j.compscitech.2019.107712.

10. Gotoh, K.; Kinumoto, T.; Fujii, E.; Yamamoto, A.; Hashimoto, H.; Ohkubo, T.; Itadani, A.; Kuroda, Y.; Ishida, H. Exfoliated Graphene Sheets Decorated with Metal-metal Oxide Nanoparticles: Simple Preparation from Cation Exchanged Graphite Oxide. Carbon 2011, 49, 1118-25, https://doi.org/10.1016/j.carbon.2010.11.017.

11. Jiang, L.; Gao, L. Fabrication and Characterization of Carbon Nanotube-Titanium Nitride Composites with Enhanced Electrical and Electrochemical Properties. J. Am. Ceram. Soc. 2006, 89, 156-161, https://doi.org/10.1111/j.1551-2916.2005.00687.x.

12. Kwok, S.W.; Goh, K.H.H.; Tan, Z.D.; Tan, S.T.M.; Tjiu, W.W.; Soh, J.Y.; Ng, G.J.G.; Chan, Y.Z.; Hui, H.K.; Goh, K.E.J. Electrically conductive filament for 3D-printed circuits and sensors. Applied Materials Today 2017, 9, 167-175, https://doi.org/10.1016/j.apmt.2017.07.001.

13. Michalska-Domańska, M.; Jóźwik, P.; Jankiewicz, B. J.; Bartosewicz. B.; Siemiaszko, D.; Stępniowski, W. J.; Bojar, Z. Study of cyclic Ni3Al catalyst pretreatment process for uniform carbon nanotubes formation and improved hydrogen yield in methanol decomposition. Materials Today: Proceedings 2016, 3S, S171S177, https://doi.org/10.1016/j.matpr.2016.02.029. 